\title{
Response to "Bacterial Adhesion and Biofilm Formation on Textured Breast Implant Shell Materials"
}

\author{
Yara Bachour $^{1}$ (D)
}

Received: 30 November 2018 / Accepted: 1 December 2018 / Published online: 13 December 2018

(C) Springer Science+Business Media, LLC, part of Springer Nature and International Society of Aesthetic Plastic Surgery 2018

Level of Evidence $V$ This journal requires that authors assign a level of evidence to each article. For a full description of these Evidence-Based Medicine ratings, please refer to the Table of Contents or the online Instructions to Authors www.springer.com/00266.

To the Editor,

I would like to congratulate Dr. James and colleagues for their paper in which they investigated bacterial adhesion on several implant shell materials [3]. I have a few comments related to the in vitro implication of their results.

First, former studies have investigated bacterial growth on smooth and textured implants after explantation, showing equal bacterial growth on both types of implants [2]. How do the authors explain these in vivo findings compared to their in vitro study?

Second, several studies have shown that capsular contracture occurs more often in smooth implants in comparison with textured implants [1]. Since it is suggested that bacteria might cause capsular contracture, one would expect more bacterial growth on (more) smooth surfaces. However, the present study shows the contrary.

Compliance with Ethical Standards

Conflict of interest I disclose no conflict of interest.

\section{References}

1. Bachour Y, Bargon CA, de Blok CJM et al (2018) Risk factors for developing capsular contracture in women after breast implant surgery: a systematic review of the literature. J Plast Reconstr Aesthet Surg 71:e29-e48

2. Jacombs A, Tahir S, Hu $\mathrm{H}$ et al (2014) In vitro and in vivo investigation of the influence of implant surface on the formation of bacterial biofilm in mammary implants. Plast Reconstr Surg 133:471e-480e

3. James GA, Boegli L, Hancock J et al (2018) Bacterial adhesion and biofilm formation on textured breast implant shell materials. Aesth Plast Surg. https://doi.org/10.1007/s00266-018-1234-7
Yara Bachour

yarabachour@gmail.com

1 Department of Plastic, Reconstructive and Hand Surgery, VU

University Medical Center, De Boelelaan 1117,

PO Box 7057, 1007 MB Amsterdam, The Netherlands 